\title{
CESAR5.3: Isotopic depletion for Research and Testing Reactor decommissioning
}

\author{
Guillaume Ritter*, Romain Eschbach, Richard Girieud, and Maxime Soulard \\ CEA, DEN, SPRC, 13108 St Paul-lez-Durance, France
}

Received: 6 July 2017 / Received in final form: 4 October 2017 / Accepted: 27 March 2018

\begin{abstract}
CESAR stands in French for "simplified depletion applied to reprocessing". The current version is now number 5.3 as it started 30 years ago from a long lasting cooperation with ORANO, co-owner of the code with CEA. This computer code can characterize several types of nuclear fuel assemblies, from the most regular PWR power plants to the most unexpected gas cooled and graphite moderated old timer research facility. Each type of fuel can also include numerous ranges of compositions like UOX, MOX, LEU or HEU. Such versatility comes from a broad catalog of cross section libraries, each corresponding to a specific reactor and fuel matrix design. CESAR goes beyond fuel characterization and can also provide an evaluation of structural materials activation. The cross-sections libraries are generated using the most refined assembly or core level transport code calculation schemes (CEA APOLLO2 or ERANOS), based on the European JEFF3.1.1 nuclear data base. Each new CESAR self shielded cross section library benefits all most recent CEA recommendations as for deterministic physics options. Resulting cross sections are organized as a function of burn up and initial fuel enrichment which allows to condensate this costly process into a series of Legendre polynomials. The final outcome is a fast, accurate and compact CESAR cross section library. Each library is fully validated, against a stochastic transport code (CEA TRIPOLI 4) if needed and against a reference depletion code (CEA DARWIN). Using CESAR does not require any of the neutron physics expertise implemented into cross section libraries generation. It is based on top quality nuclear data (JEFF3.1.1 for $\sim 400$ isotopes) and includes up to date Bateman equation solving algorithms. However, defining a CESAR computation case can be very straightforward. Most results are only 3 steps away from any beginner's ambition: Initial composition, in core depletion and pool decay scenario. On top of a simple utilization architecture, CESAR includes a portable Graphical User Interface which can be broadly deployed in R\&D or industrial facilities. Aging facilities currently face decommissioning and dismantling issues. This way to the end of the nuclear fuel cycle requires a careful assessment of source terms in the fuel, core structures and all parts of a facility that must be disposed of with "industrial nuclear" constraints. In that perspective, several CESAR cross section libraries were constructed for early CEA Research and Testing Reactors (RTR's). The aim of this paper is to describe how CESAR operates and how it can be used to help these facilities care for waste disposal, nuclear materials transport or basic safety cases. The test case will be based on the PHEBUS Facility located at CEA - Cadarache.
\end{abstract}

\section{Introduction}

The CESAR project was initiated about 30 years ago as a cooperative action conducted both by French CEA (Atomic Energy Commission) and ORANO. It was dedicated to characterize the flow of isotopes coming through the La Hague Nuclear Fuel Reprocessing Plant in France/region of Normandy. Basically from a used fuel sub-assembly to the associated recycled MOX and the different cans of waste.

\footnotetext{
* e-mail: Guillaume.Ritter@CEA.Fr
}

At the beginning, only a few heavy nuclides were treated. Then, step by step, Fission Products and other Structural Materials or Impurities were added to the list, so that, as of today, the fate of 486 isotopes can be computed fast and accurately.

CESAR provides isotopic concentrations and all physics parameters that can be drawn like IAEA Safety transportation class, decay heat or gamma emissions. Such results then proved to be useful not only for the fuel cycle industry but also in much smaller facilities like CEA fuel engineering hot cells, severe accident experiments or Research and Testing Reactor (RTR's).

The goal of this paper is to show how CESAR works, what it produces and how helpful it can be for unusual uses 


$$
\begin{aligned}
& \frac{d N(t)}{d t}\left[\begin{array}{l}
A \\
Z
\end{array}\right]=\Phi(t) \cdot\left[\sigma_{c}(t) \cdot N(t)\right]_{\left[\begin{array}{l}
A-1 \\
Z
\end{array}\right]}+\Phi(t) \cdot\left[\sigma_{n, 2 n}(t) \cdot N(t)\right]_{\left[\begin{array}{l}
A+1 \\
Z
\end{array}\right]} \\
& +\left[\lambda_{\beta^{+}} \cdot N(t)\right]_{\left[\begin{array}{l}
A \\
Z+1
\end{array}\right]}+\left[\lambda_{\beta^{-}} \cdot N(t)\right]_{\left[\begin{array}{l}
A \\
Z-1
\end{array}\right]}+\left[\lambda_{\alpha} \cdot N(t)\right]_{\left[\begin{array}{l}
A+4 \\
Z+2
\end{array}\right]}+\left[\lambda_{T I} \cdot N(t)\right]_{\left[\begin{array}{l}
A^{m} \\
Z
\end{array}\right]}
\end{aligned}
$$

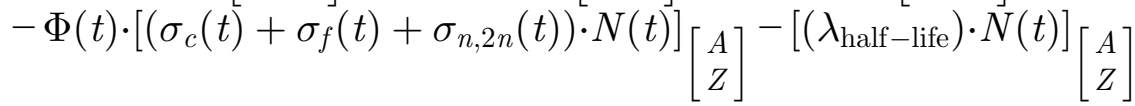

in operation and dismantling of RTR's. Evaluation of mass inventory, activity, decay heat, radiation sources are necessary to operate a facility on a day-to-day basis. But dismantling also requires evaluations of biological shielding, decay heat removal, reprocessing, transport, safety classification, waste interim storage or disposal. The last main version of CESAR was released in 2012 [1]. The new issue for CESAR is neither a recently updated Graphical User Interface (2015) nor a new simplified dose rate computation module (2016) but rather being used in a different industrial environment (RTR decommissioning) than before (mostly recycling).

\section{Depletion and decay made easy}

The goal of this chapter is to address the means by which CESAR characterizes isotopic inventories. This process takes place either during in-core fuel burn up or outside of the neutron flux, where natural radioactive decay happens.

\subsection{Isotopic evolution}

CESAR solves the standard Bateman depletion equation [2], applied to reactor operations as in the following form (applicable to e.g. actinides):

\section{See equation (1) above}

where
$-N(t)=$ concentration of an isotope $\left[\begin{array}{l}A \\ Z\end{array}\right]$ at time " $t$ ";
$-\varphi(t)=$ neutrons flux at time " $t$ ";

$-\varphi(t)=$ neutrons flux at time " $t$ ";

$-\sigma(t)=$ cross section at time " $t$ ";

$-\lambda=$ half life decay constant.

In equation (1), an illustration of isotopic evolutions taking place under neutron flux is exposed. This illustration is not comprehensive. Cross sections correspond to a set of typical reactions under neutron flux. Such reactions include neutron capture, $n-2 n$ scattering and fission.

For fission products and for some activation products, this system includes a global fission yield (see Eq. (2)), operating as a sum of the fission rate of a fissionable actinide multiplied by the fission yields of the fission product for this fissionable actinide.

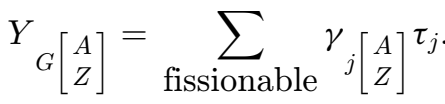

$$
\begin{aligned}
& \text { actinides } \\
& \text { j }
\end{aligned}
$$

where:

$-\tau_{j}=$ fission rate of the fissile nucleus " $j$ ";

$-\gamma_{j}=$ Production yield of isotope $\left[\begin{array}{l}A \\ Z\end{array}\right]$ from fissile nucleus $j$.

For activation products, other reaction types $[(n, \alpha)$, $(n, p), \ldots]$ are taken into account.

Solving equation (1) provides isotopic concentrations for heavy nuclides, fission products, impurities and activated structural materials.

All basic nuclear data comes from [3]; $2 / 3$ fission yields are cumulated and $1 / 3$ are independent.

Two different types of solvers have been developed to care for either in-core depletion or off-core decay (cf. Sect. 2.2).

\subsection{Computation}

In-core depletion is solved using the Runge Kutta 4th order method and off core decay is solved using a matrix exponential method, more specifically with a Taylor Series type of algorithm [4].

In both cases, the overall isotopic matrix is split in several smaller easier to solve systems which makes computations faster. As an example, characterizing the behaviour for a typical UOX $17 \times 17$ PWR sub-assembly takes less than 20 s without optimization on a desktop computer (e.g. Dell Precision Tower 7810 with Linux 3.16.0-4-amd64 \#1 SMP Debian 3.16.43-2 ×86 64 GNU/Linux running onto 8 processors type Intel(R) Xeon(R) CPU E5-2637 v3 @ $3.50 \mathrm{GHz}$ and $32 \mathrm{~Gb}$ Memory).

Hypotheses for this computation are given in the following table.

Running the same case using a touchscreen, instead of usual mouse and keyboard, yields identical performance.

The other complementary reason for fast computations is all decay chains are included in the executable software, forgetting about numerous disk access losses to an external file during a run. Moreover, chains are cut to an optimum to save on computation time whilst preserving predictivity. 
And as computations do not all require the comprehensive list of CESAR isotopes to go even faster, it is possible to skip (or add) a hundred more actinides (from ${ }^{206} \mathrm{~Pb}$ to ${ }^{257} \mathrm{Fm}$ ) and their spontaneous fission for long cooling times.

Last to be mentioned, but not the least, the trickiest parameter as for core physics i.e. microscopic cross sections, are (almost) not computed during this Bateman step, as will be described in Section 3. This saves at least 99\% computer time.

After solving the Bateman equation, users seldom simply need isotopic concentrations. This is why computations can continue to produce all complementary parameters, as described hereafter.

\subsection{What results beyond isotopic concentrations}

Users can draw from concentrations all the following parameters:

- mass inventory;

- activity $(\alpha, \beta$, Isomeric Transitions);

- decay heat $(\alpha, \beta, \gamma)$;

- neutron, $\alpha$ and $\gamma$ source and spectrum, including ray spectrum (spontaneous fission and $(\alpha, n)$ reactions in oxide fuel);

- dose rate at $1 \mathrm{~m}$ in air for a point source;

- radiotoxicity source;

- coefficients used for the transport of nuclear material;

- coefficients used for the classification of radioactive substances.

CESAR provides fast and abundant results. Uncertainties are computed outside, within the DARWIN package, on which CESAR is validated (cf. Sect. 3.2).

\section{CESAR cross section libraries}

The goal of this chapter is to present how CESAR cross sections are elaborated, packed as dedicated libraries and eventually validated.

\subsection{Generation}

Cross sections in equation (1) correspond to reactions caused by neutrons, i.e. occurring during in-core burnup. Therefore, it has to account for neutron physics phenomena due to the flux distribution.

Assessment of the cross sections is performed by CEA scientific staff with dedicated reactor lattice physics computer codes like CEA APOLLO ${ }^{\mathrm{TM}}[5]$ or ERANOS ${ }^{\mathrm{TM}}$ [6]. Characterization of any original new core design can take months, from technological data collection to the end. Basic nuclear data come from [3], just as for depletion. Only reactor worth isotopes are characterized during this process. It concerns $\sim 100$ isotopes that have a significant influence on reactivity.

Choosing the appropriate code depends on the expected core physics (fast or thermal spectrum). Determination of cross sections requires an accurate modelling of the fuel geometry (in most cases 2D), with adapted space mesh, boundary conditions and energy binning as well as appropriate isotope-wise self-shielding options. In the case of e.g. BWR concepts, it is also necessary to define a 3D model in order to include modelling of axial void effects.

Cross sections are computed at each step of burn up so that any light change in the flux distribution due to fission products build up, heavy nuclides depletion or e.g. boron concentration evolution can be safely accounted for. It is also computed for several initial enrichments or isotopic vectors, each causing a different shape of neutron spectrum at the beginning of life and during depletion. This energy wise spectrum is recorded as a representative signature of core physics conditions.

At the end of this part, cross sections

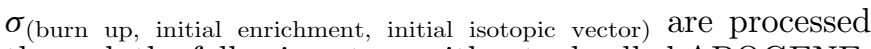
through the following steps with a tool called APOGENE:

- collapsing in one energy group using the computed neutron energy spectrum. This operation concerns both $\sim 100$ reactor worth isotopes and all other $\sim 400$ isotopes among CESAR's for which an infinite dilution "general purpose" $\sigma$ exists [3].

- fitting one group cross sections

$\sigma_{\text {(burn up, initial enrichment, initial isotopic vector) }}$ to Legendre polynomials and extracting the corresponding coefficients. More precisely, it determines a set of coefficient degrees providing results closest to the original figure.

- ciphering the coefficients;

- packing the whole into a dedicated CESAR cross section library, called a BBL.

Figure 1 next page shows how CESAR cross section libraries are generated.

After this process, it can be used with CESAR to determine the isotopic inventory.

On top of this process, another step is added to make sure predictions are valid, as described in the following chapter.

\subsection{Validation process}

CESAR uses generic radioactive decay data from [3] and specific cross sections estimated thanks to Legendre polynomials as described in the previous chapter.

However, it must be checked whether a short list of 500 isotopes, only accounting for independent fission yields, cumulated with polynomials estimated cross sections succeeds in providing technically affordable results.

This is why CESAR is validated against DARWIN ${ }^{\mathrm{TM}}$ $[1,7,8]$, CEA reference computer package for isotopic inventory evolution.

DARWIN $^{\mathrm{TM}}$ computes all 3800 isotopes from JEFF3.1.1. It includes independent fission product yields with their comprehensive decay chain and its results are successfully compared to experimental data coming from several types of irradiated fuel section dissolution chemical analysis programs. Some DARWIN results are also currently undergoing a growing uncertainty analysis programme [9].

After generating new CESAR $\sigma$ libraries, results from both CESAR and DARWIN corresponding to the same test case are controlled in order to check consistency. Possible slight discrepancies only concern a handful of isotopes with 


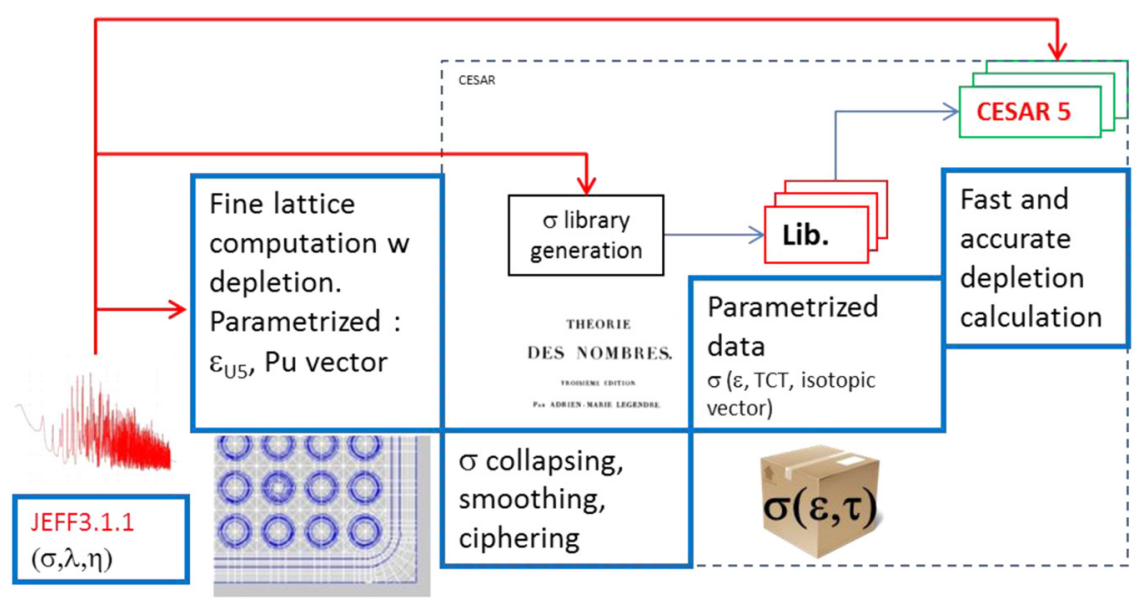

Fig. 1. Cross section generation process.

Table 1. Reference computation hypotheses for code performance characterization.

\begin{tabular}{|c|c|c|}
\hline Fuel features ( 1 medium) & Irradiation history & Requested output \\
\hline $\begin{array}{l}\text { UOX: mass fractions } 3.5 \% \\
{ }^{235} \mathrm{U}+96.5 \%{ }^{238} \mathrm{U}\end{array}$ & $\begin{array}{l}3 \text { consecutive in-core cycles, each } \\
\text { including } 330 \text { days at average power }\end{array}$ & $\begin{array}{l}\text { Isotopic concentrations of all nuclides } \\
\text { (Heavy Nuclides, Fission Products and }\end{array}$ \\
\hline $\begin{array}{l}\text { Total mass } 1 \mathrm{~T}_{\mathrm{HM}} \\
\text { Fuel impurities: } 190 \mathrm{ppm} \text { of } \\
\text { oxide initial mass }\end{array}$ & $\begin{array}{l}33 \mathrm{~W} / \mathrm{g}_{\text {HM }} \text { followed by } 35 \text { inter-cycle } \\
\text { days at } 0 \text { power. Then } 3 \text { years in pool } \\
\text { cooling period }\end{array}$ & $\begin{array}{l}\text { Activation of fuel impurities by- } \\
\text { products) at end of cooling. } 486 \text { isotopes } \\
\text { computed. }\end{array}$ \\
\hline
\end{tabular}

significant concentrations and are then of the order of a few $\%$. For other isotopes, concentrations or offsets are much lower and neglected. Such figures will be discussed in deeper details in the chapter pertaining to the PHEBUS facility.

This procedure can be complemented with computer random testing of the new CESAR library. It will concern $\sim 1000$ cases checking whether the code actually operates within the assigned domain and fails outside.

As a consequence, CESAR straightly benefits all the outcome of the comprehensive effort dedicated to improving DARWIN results as compared to measurements and to reducing all associated uncertainties.

\section{The graphical user interface}

This chapter is dedicated to potential CESAR users and aims at showing how anyone in a decommissioning facility can set up a computation and get good results.

This GUI is a graphical computer application that makes filling CESAR input files and understanding and exploiting CESAR output files as easy as ordering an item on a commercial sales internet URL.

\subsection{Main features}

This Graphical User Interface was updated in 2016 to include $\gamma$ dose rate in air at $1 \mathrm{~m}$ for a point source.

CESAR can be launched by experts in a computer batch process with a dedicated input deck. However, the interface makes it easier to use on about any common platform (Linux, Windows, Apple).
It was developed in $\mathrm{C}++$ with Open source QT5 technology [10], which makes it compatible with numerous other applications like CEA platform SALOME [11]. It is touch screen compatible. Exchange file format is xml thus providing a large flexibility. Drag and drop can be used between most parameters and users will have instant online help with generalized tooltips.

\subsection{Using it}

A typical computation is based on 2 steps : 1st generating a set of isotopic concentrations as a function of compound history; 2nd extracting any desired data from concentrations.

The input of a CESAR computation includes initial compositions, a selection of cross section library and a description of irradiation and/or decay history.

Isotopic initial compositions can be entered in several units (Absolute mass, Atoms/cc, Mass \%, Atom \%, TBq), all dynamically proportional.

It can be located off exposure to any neutron flux or within a reactor core.

In that later case, users have to select a cross sections set matching their hypotheses in the available catalog of core designs. At CEA, about 100 such libraries (BBL) have already been generated (see Tab. 2 hereafter). Such developments were led either in collaboration with ORANO, or exclusively for ORANO, or exclusively for $C E A$.

Elaborating the compound history consists in adding consecutive phases corresponding either to in-core burn up 
Table 2. Main core design libraries developed at CEA.

\begin{tabular}{|c|c|c|}
\hline Fuel/Reactor & $\begin{array}{l}\text { Initial U-235 or } \mathrm{Pu} \text { enrichment } \\
\text { Maximum burnup }\end{array}$ & Note \\
\hline $\begin{array}{l}\text { PWR UOX } \\
\text { (fuel) }\end{array}$ & $\begin{array}{l}\text { Up to } 5 \% \\
\text { Up to } 100 \mathrm{GWd} / \mathrm{t}\end{array}$ & $\begin{array}{l}17 \times 17 \text { but also } 14 \times 14,15 \times 15,16 \times 16,18 \times 18 \text {, and } \\
\text { reprocessing uranium based fuel, etc, } \ldots\end{array}$ \\
\hline $\begin{array}{l}\text { Subassembly } \\
\text { structures }\end{array}$ & $\begin{array}{l}\text { Up to } 5 \%(\text { UOX PWR) and } 12 \% \\
(\mathrm{MOX}, \mathrm{FBR}) \mathrm{Up} \text { to } 100 \mathrm{GWd} / \mathrm{t}\end{array}$ & $\begin{array}{l}\text { Libraries divided into different parts: Top nozzle, spring } \\
\text { plug, plenum, clads and grids, bottom end plug, bottom } \\
\text { nozzle }\end{array}$ \\
\hline BWR UOX & $\mathrm{Up}$ to $4.5 \% \mathrm{Up}$ to $72 \mathrm{GWd} / \mathrm{t}$ & $\begin{array}{l}9 \times 9,8 \times 8 \text {. Libraries divided into different parts to account } \\
\text { for axial heterogeneity (void fraction or initial } \\
\text { composition). Burn-up also has an influence on axial power } \\
\text { level. }\end{array}$ \\
\hline PWR MOX & Up to $12 \%$ Up to $100 \mathrm{GWd} / \mathrm{t}$ & $\begin{array}{l}17 \times 17 \text { but also } 14 \times 14,15 \times 15,16 \times 16 \text { Effects of initial } \\
\text { plutonium composition on cross section sets are taken into } \\
\text { account. }\end{array}$ \\
\hline BWR MOX & Up to $6.1 \% \mathrm{Up}$ to $50 \mathrm{GWd} / \mathrm{t}$ & $\begin{array}{l}\text { Libraries divided into different parts to account for axial } \\
\text { heterogeneity (void fraction or initial composition). }\end{array}$ \\
\hline Heavy Water & Up to $94 \% \mathrm{Up}$ to $440 \mathrm{GWd} / \mathrm{t}$ & French and foreign experimental old reactors \\
\hline Fast Reactor & Up to $25 \% \mathrm{Up}$ to $200 \mathrm{GWd} / \mathrm{t}$ & Phenix, RAPSODIE, European Fast Reactor \\
\hline \multicolumn{2}{|c|}{ Gas Cooled ReactorUp to $1,7 \%$ Up to $11 \mathrm{GWd} / \mathrm{t}$} & $\begin{array}{l}\text { Metallic fuel, Graphite moderator, Low enrichment } \\
\text { uranium }\end{array}$ \\
\hline MTR & Up to $94 \% \mathrm{Up}$ to $1000 \mathrm{GWd} / \mathrm{t}$ & Rods, flat or cylindrical plates experimental facilities \\
\hline
\end{tabular}

or decay anywhere: cooling or storage in a pool or e.g. in a repository. Users just have to enter duration and burn up or power rate of each phase.

Any depletion computation set up can be saved under text or xml formats.

Setting CESAR output parameters comes afterwards.

The resulting computed concentrations are processed to extract all needed data (cf. Sect. 2.3). In that perspective, such parameters can be selected from a complete table as shown in following Figure 2. This selection window allows choosing which parameter in which unit will be useful. It provides output results both in a text mode including as many tables as desired and in a csv or xml format which make it compatible with numerous other applications, including previous versions of the Graphical User Interface. A basic plot function can be activated for any of all desired isotopes and parameters. Results can be sorted either alphabetically (e.g. to find an isotope) or numerically (for example, to identify a main contributor to $\gamma$ dose rate after 10 years decay).

This post processing set up is also saved under text or xml format. It includes all hypotheses from initial composition and compound history to e.g. $\gamma$ emission spectrum binning in energy or isotopic contribution to $\beta$ decay $+\gamma$ heat.

Isotopic evolution studies can be performed in a user's office as well as on the field with a portable computer or a touch screen tablet.

CESAR does not require any of core neutron physics or nuclear data knowledge and it actually proves to be user friendly on a day to day basis.

\section{Decommissioning Research and Testing Reactors at CEA}

\subsection{Description of those facilities concerned with dismantling}

At CEA, the RTR fleet was mostly designed and built in the 1960's-1970's and several facilities have now stopped operations.

Some reactors are still operating like ORPHEE ${ }^{1}$, a high flux beam core in Saclay or CABRI, a reactivity transient test reactor with a pressurized water loop in Cadarache, which is currently being renovated.

For decommissioning facilities, it is essential to generate dedicated cross sections in order to be able to quantify fuel isotopic inventories stored in decay pools or in hot cells.

Among the reactors for which decommissioning has started, those given in the following Table 2 already have a fuel characterization library available for CESAR - although these were mostly developed for fuel recycling purposes.

In this part, CESAR computations applied to PHEBUS and CABRI will be presented and analysed.

\subsection{How does CESAR help}

In facilities presented in Table 3, the core has already been unloaded. Fuel sub assemblies may be stored in a decay pool or in a dry storage facility.

${ }^{1}$ These libraries have been developed specifically for ORANO, for reprocessing at La Hague plant purposes. 


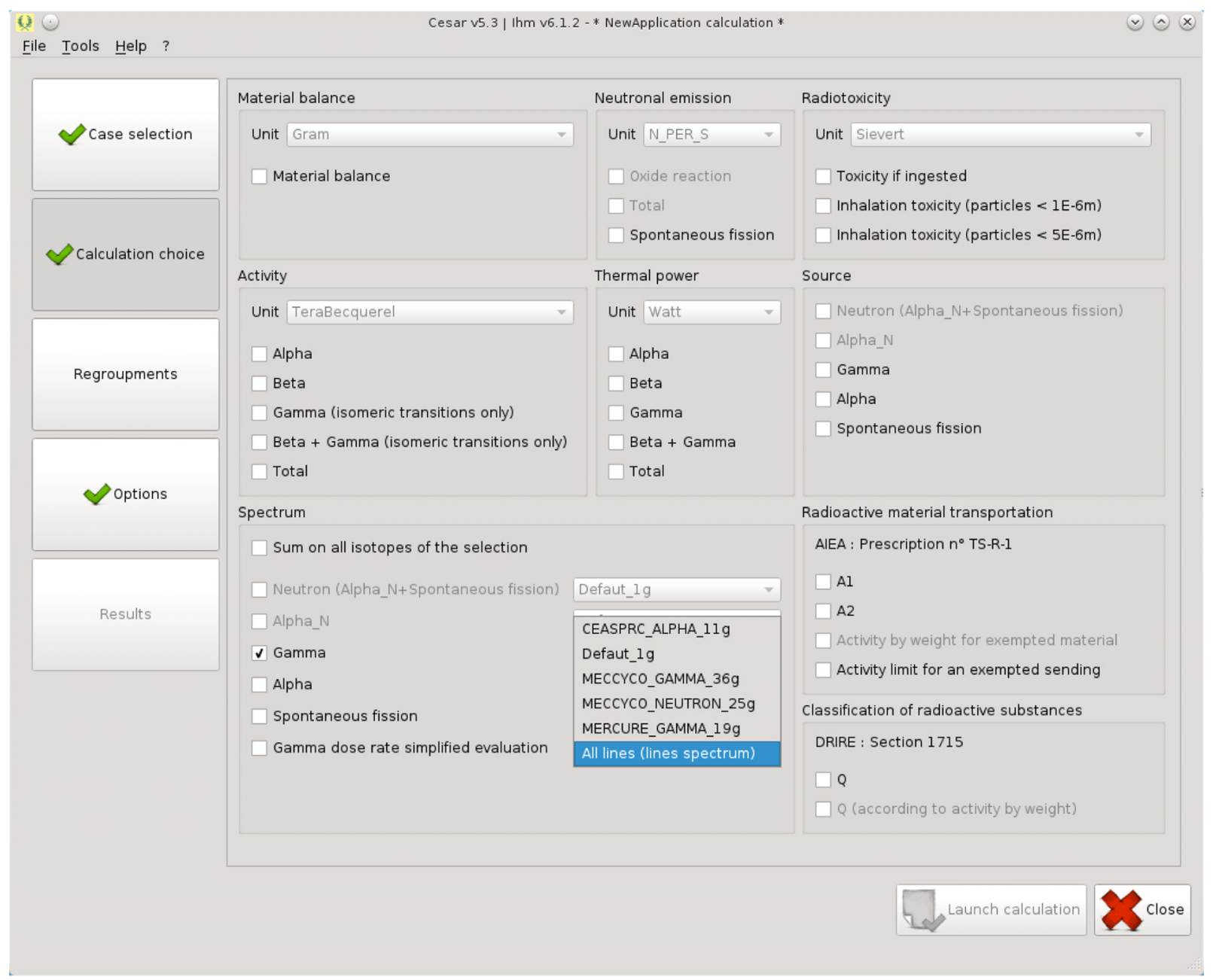

Fig. 2. Selection of desired parameters.

Table 3. CESAR libraries dedicated to CEA reactors.

\begin{tabular}{|c|c|c|}
\hline Type of reactor & Name & $\begin{array}{l}\text { Fuel design } \\
\text { main features }\end{array}$ \\
\hline$\overline{M T R}$ & OSIRIS $^{1}$ & $\begin{array}{l}\text { Plates (High or Low } \\
\text { enrichment fuel) }\end{array}$ \\
\hline MTR & SILOE $^{1}$ & Plates \\
\hline $\begin{array}{l}\text { Severe accident } \\
\text { testing }\end{array}$ & SCARABEE $^{1}$ & Plates \\
\hline Teaching & ULYSSE $^{1}$ & Plates \\
\hline $\begin{array}{l}\text { Severe accident } \\
\text { testing }\end{array}$ & PHEBUS & Rods + grids \\
\hline GCR Demonstrator & EL3 & Rods \\
\hline FBR Demonstrator & RAPSODIE $^{1}$ & Pins \\
\hline
\end{tabular}

There may also be equipments contaminated from the same fuel located e.g. in an interim waste storage warehouse. And eventually, experiments may have been conducted within the flux range of that same fuel and will have to be disposed of.

Here is a short list of other general situations where a depletion / decay computation can be useful:
- evaluation of a neutron source $\left({ }^{252} \mathrm{Cf}\right.$ or Am-Be) activity or neutron emissions either to update the nuclear materials inventory or to transfer it to another facility;

- balance of nuclear materials entering or leaving the facility, as future or current owner;

- assessment of Isotopic rejects to wastes (vents stack, liquid waste tank);

- evaluation of decay heat;

- gas activity (tritium, fission products, $\mathrm{Cl}, \mathrm{C}$ );

- gamma spectrum emission prior to dose calculations;

- licensing of new experiments/tricky operations or transport casks;

- criticality, decay heat and radiation shielding parameters evaluation;

- waste inventory;

- ion exchange resins and filters activity.

\subsection{The case of PHEBUS}

The PHEBUS reactor started operations in 1977. It was dedicated to the simulation of severe accidents, including Loss Of Coolant Accident, fuel bundle degradation and melting. 


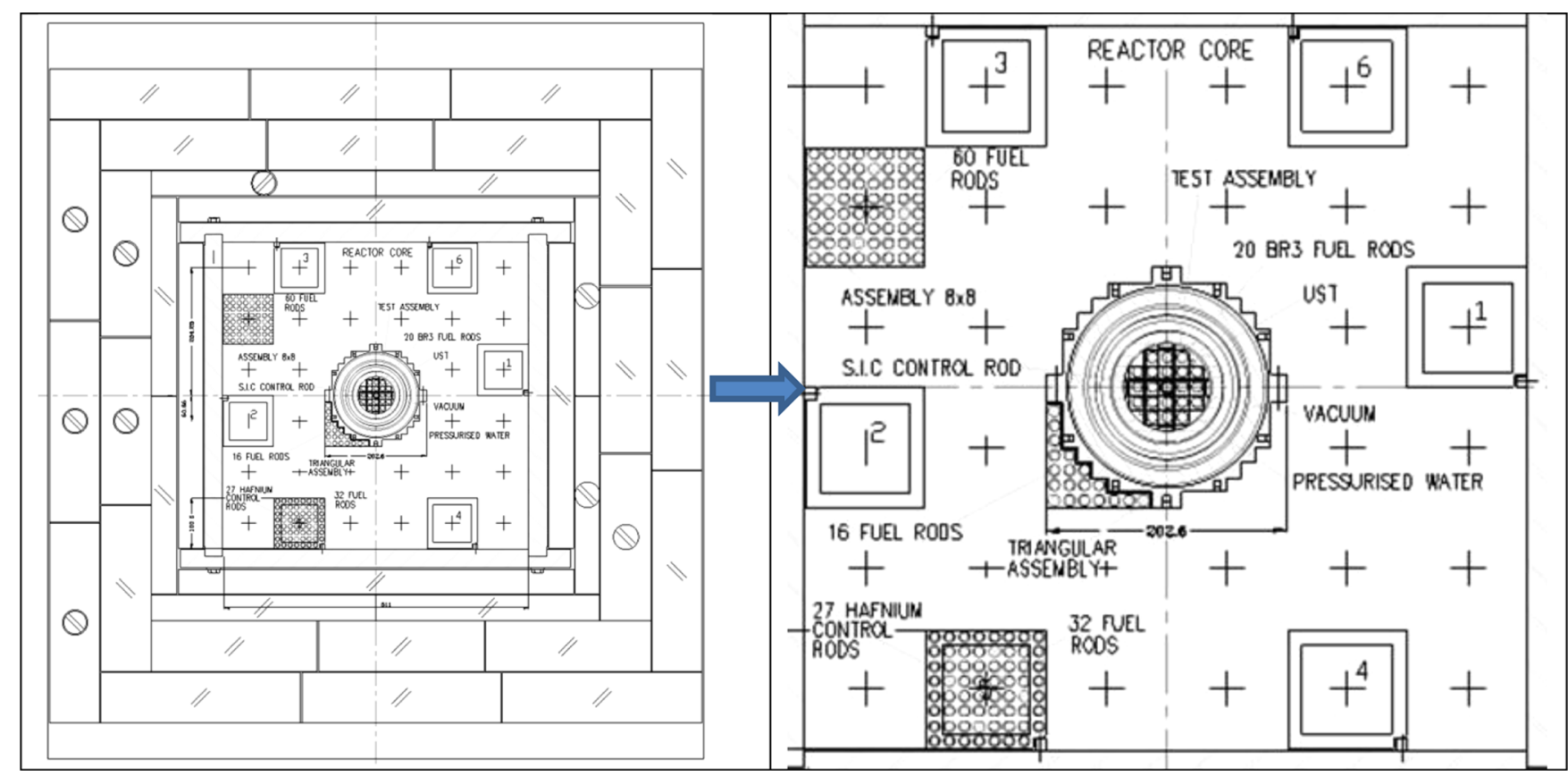

Fig. 3. PHEBUS core lay out.

It was a pool reactor with an annular core. Experiments were performed in a dedicated pressurized water loop located at the core centre. The core (cf. Fig. 3) operated with 3 types of fuel sub-assemblies: Standard element $(8 \times 8)$, Triangular element and Control rods element. The fuel was $\mathrm{UO}_{2}$ in zircaloy cladding.

It produced experimental data from the mid 1960's up to 2004 [10]. A last criticality campaign was performed in 2007 and the fuel sub-assemblies were eventually transferred from the core vessel to a nearby storage pool in late 2012 .

Sub assemblies must all and individually be characterized in terms of isotopic inventory in order to be evacuated from their current location to a facility dedicated to rods extraction. In that perspective, they have to be loaded in a transport cask, which will be carried on a truck and delivered to the extraction facility hot cell. Each subassembly has a specific peaking factor and burn up and must be dealt with according to a dedicated CESAR computation.

This basic 3 step operation (transfer to the cask - road transportation - transfer to the hot cell of another facility) requires several CESAR computations to be inserted in separate and dedicated safety cases.

Typically, each part of the safety case requires a specific CESAR computation:

- nuclear materials inventory: Initial and current isotopic mass inventory for all isotopes;

- basic radiation protection study to minimize risks to personnel: Evaluation of overall $\gamma$ sources $+\gamma$ dose from

${ }^{154} \mathrm{Eu}$ and from ${ }^{137} \mathrm{Ba}_{\mathrm{m}}$ in air at the decay date of transfer;

- loading into the cask may require checking some criticality features: initial and current fissile content $\left({ }^{235} \mathrm{U}+\mathrm{Pu}\right)$

- source term for potential gas releases at decay date of transfer: IAEA A2 value for gaseous or volatile fission products. Mass activity of ${ }^{3} \mathrm{H}$ and ${ }^{85} \mathrm{Kr}$;

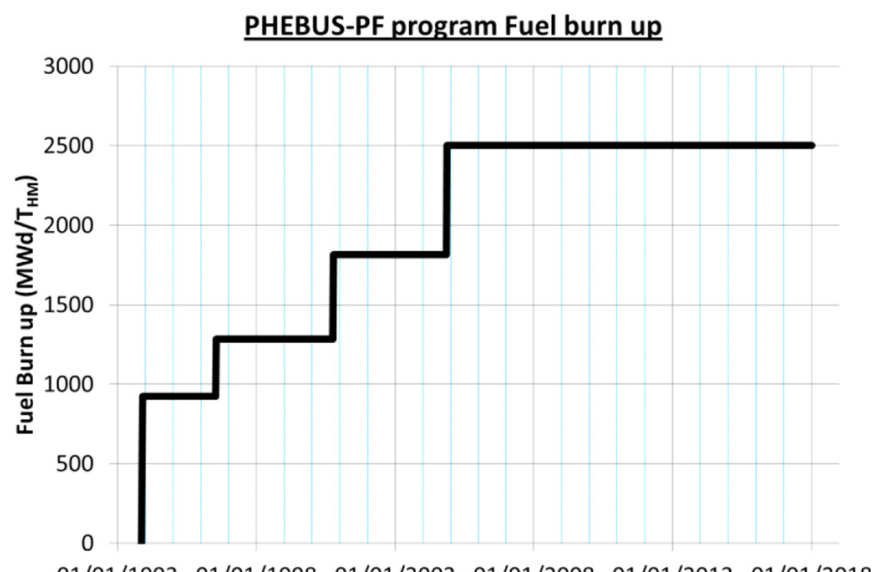

01/01/1993 01/01/1998 01/01/2003 01/01/2008 01/01/2013 01/01/2018

Fig. 4. PHEBUS - FP program fuel burn up.

- cask ability for transportation of such content: Decay heat, Activity and neutron emissions from Heavy Nuclides and Activation and Fission products.

Each operator (sender - carrier - receiver) is clearly responsible for characterizing and checking these parameters. Using the same tool helps finding occasional mistakes in evaluation.

The PHEBUS facility operated during 4 short periods for the PHEBUS - FP program, so that final fuel depletion is 2,5 $\mathrm{GWj} / \mathrm{T}$. It took about 4 years recommissioning the facility between each phase of the program and the cooling time since shutdown has also been accounted in CESAR computations (cf. Fig. 4). Programs anterior to PHEBUS FP have been integrated to the overall fuel burn up.

Figure 4 shows the PHEBUS facility did not cumulate a very high burn up, as compared to industrial power reactors. On top of that, it operated with a very specific power history, including a long decay since 


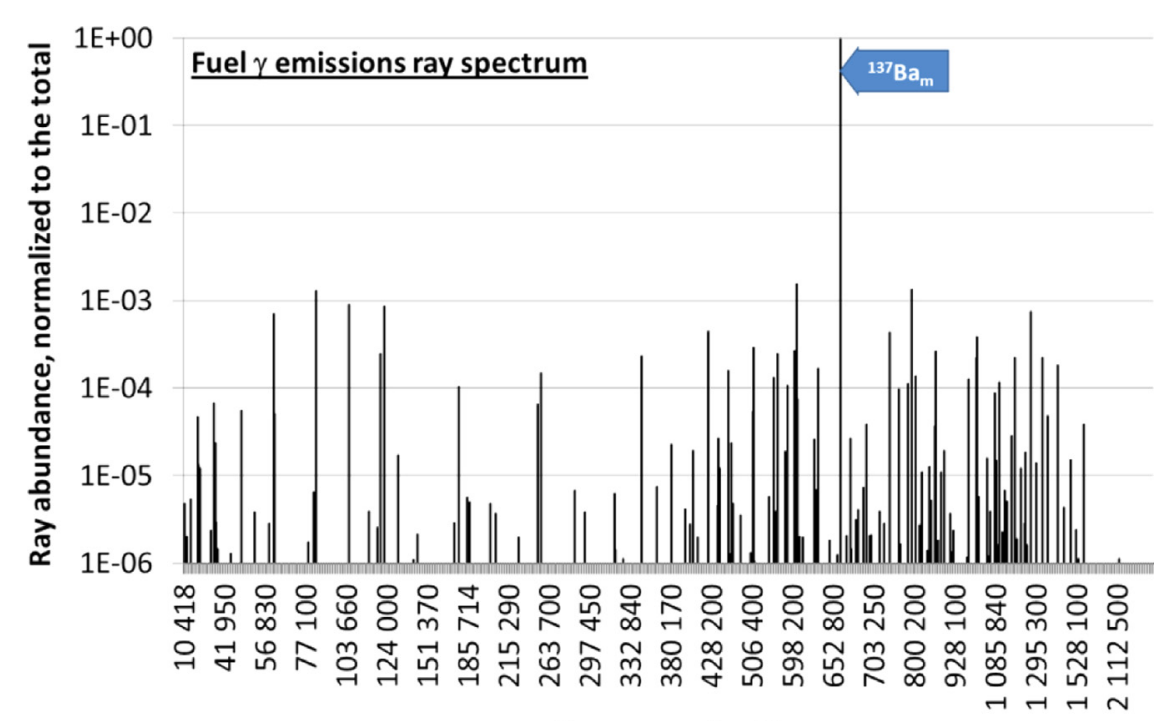

Ray energy in eV

Fig. 5. PHEBUS fuel typical $\gamma$ emissions (Ray spectrum).

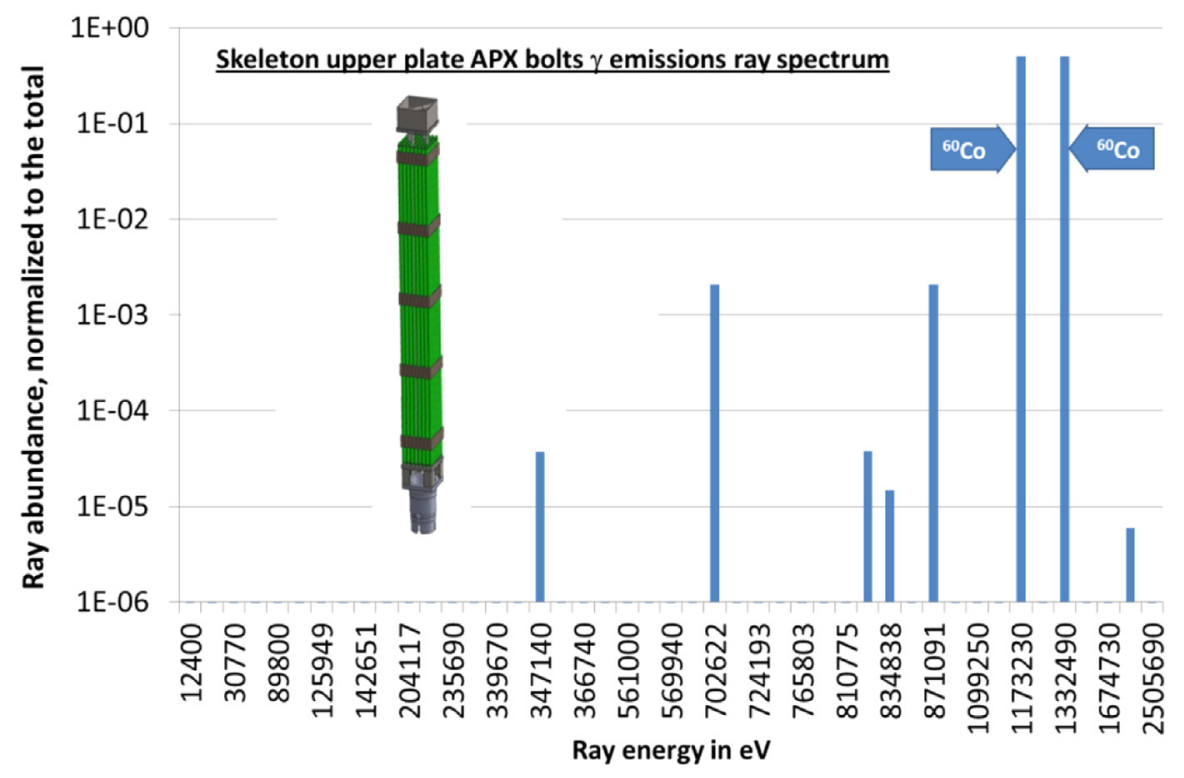

Fig. 6. PHEBUS sub-assembly skeleton typical $\gamma$ emissions (Ray spectrum).

shutdown, which makes a dedicated depletion computation mandatory.

Validation results are given here for fuel cross section libraries :

The maximum offset between cross sections coming from APOLLO2 [5] transport calculations and from Legendre polynomials as a function of burn-up (cf. Sect. 3.1 ) is $1 \%$. The offset between DARWIN [7] and CESAR concentrations, computed almost at the end of irradiation (2500 MW.D/T), is lower than $2.90 \%$ except for 18 Heavy Nuclides with concentrations $<10^{13}$ atoms $/$ cc and for 14 Fission Products with concentrations $<10^{15}$ atoms $/ \mathrm{cc}$, which is negligible and allows using the library.

CESAR was used to provide Activity, Decay heat, neutron and $\gamma$ emissions for each fuel sub-assembly. It also computed the activation of corresponding fuel skeletons.

As a result, an ordinary PHEBUS sub-assembly will have, as of mid November 2017, an activity of $19,5 \mathrm{TBq}$ (98\% from Fission Products). The decay heat will be $1,51 \mathrm{~W}\left(94 \%\right.$ from ${ }^{90} \mathrm{Y},{ }^{137} \mathrm{Ba}_{\mathrm{m}},{ }^{137} \mathrm{Cs}$ and $\left.{ }^{90} \mathrm{Sr}\right)$ and total neutron emissions will be $3080 \mathrm{n} / \mathrm{s}$.

In the fuel the typical spectrum of $\gamma$ emissions is given by CESAR in Figure 5 .

Figure 5 reminds ${ }^{137} \mathrm{Ba}_{\mathrm{m}}$ is by far responsible for most of gamma emissions from the fuel.

In the skeleton of a fuel sub-assembly, the typical spectrum of $\gamma$ emissions is given by CESAR in Figure 6 .

Figure 6 reminds ${ }^{60} \mathrm{Co}$ is the main contributor to $\gamma$ emissions due to structural materials activation. CESAR 


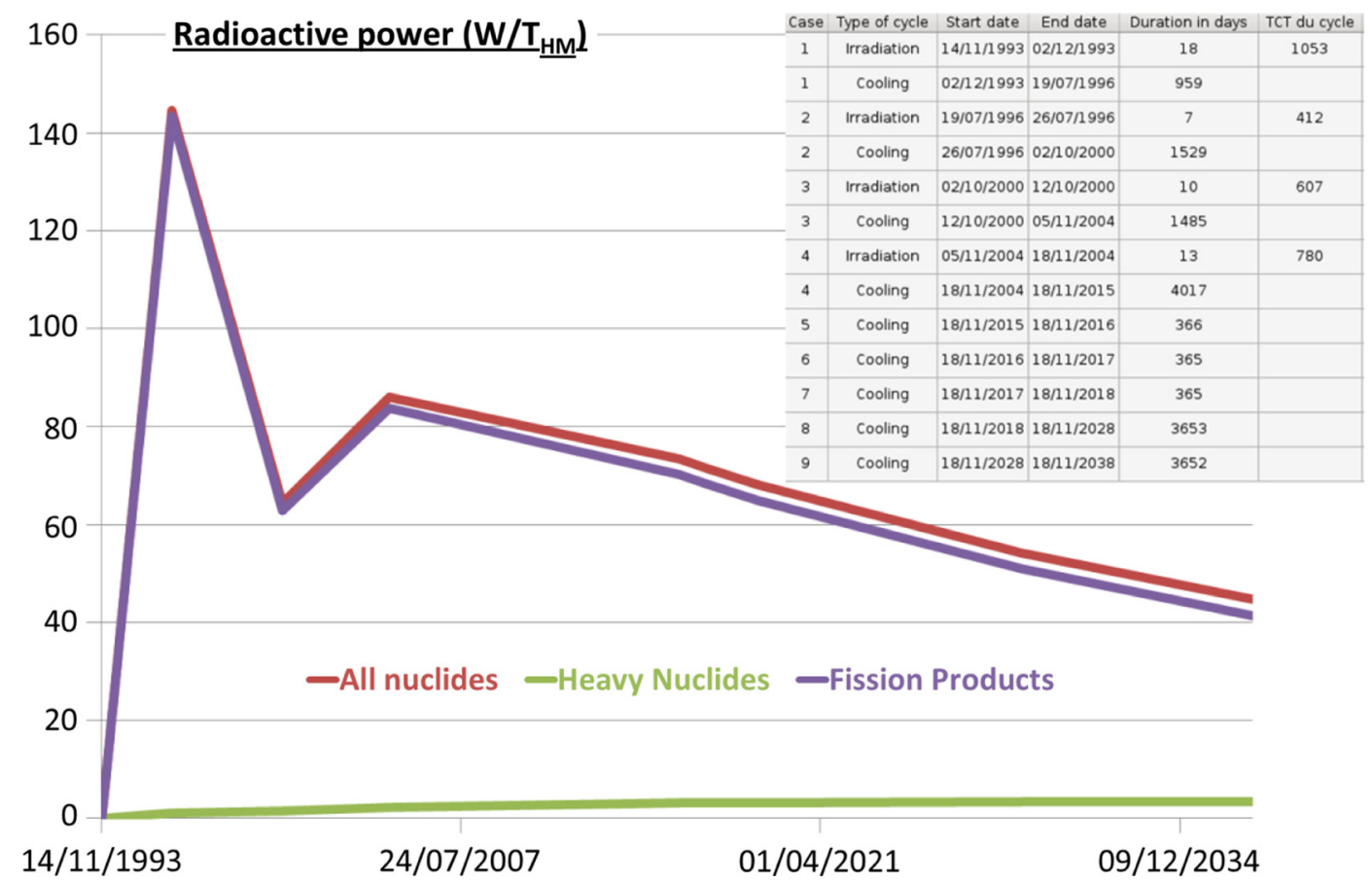

Fig. 7. PHEBUS standard $8 \times 8$ fuel sub-assembly decay heat as a function of time.

also provides a simplified evaluation of dose rate at $1 \mathrm{~m}$, in air, with the point source approximation. The dose rate due to one bolt $(30 \mathrm{~g})$ under such conditions is $0.7 \mu \mathrm{Gy} / \mathrm{h}$.

Values computed by CESAR and given above are predictions in order to organize transportation and decommissioning of the facility. It has not been compared to any measurement yet.

CESAR results for decommissioning or transport applications are in general limited to regulatory requirements and do not include a comprehensive list of possible outputs, as might appear for instance in a code comparison benchmark.

The following list gives most radiological data required to fulfil the transport case for fuel sub-assemblies:

- mass fraction of ${ }^{234} \mathrm{U},{ }^{235} \mathrm{U},{ }^{238} \mathrm{U}$ before irradiation;

- mass fraction of ${ }^{234} \mathrm{U},{ }^{235} \mathrm{U},{ }^{238} \mathrm{U}, \mathrm{Pu} / \mathrm{U}+\mathrm{Pu},{ }^{238} \mathrm{Pu}$, ${ }^{239} \mathrm{Pu},{ }^{240} \mathrm{Pu},{ }^{241} \mathrm{Pu},{ }^{242} \mathrm{Pu},{ }^{241} \mathrm{Am}$ after irradiation;

- total activity for Heavy Nuclides, Fission products and Activation products;

- total decay heat for Heavy Nuclides, Fission products and Activation products;

- total activity for Heavy Nuclides, Fission products and Activation products as well as individual activity from ${ }^{154} \mathrm{Eu}$ and ${ }^{137} \mathrm{Ba}_{\mathrm{m}}$;

- total neutron emissions coming from $\boldsymbol{\alpha}, \boldsymbol{n}$ reactions onto oxygen (in oxide fuels) and from spontaneous fission;

- total simplified dose rate at $1 \mathrm{~m}$ and individually from ${ }^{154} \mathrm{Eu},{ }^{137} \mathrm{Ba}_{\mathrm{m}}$;

- activity for specific gases like ${ }^{3} \mathrm{H}$ and ${ }^{85} \mathrm{Kr}$;

- massic activity for ${ }^{241} \mathrm{Am},{ }^{242} \mathrm{Am}_{\mathrm{m}},{ }^{243} \mathrm{Am},{ }^{242} \mathrm{Cm},{ }^{244} \mathrm{Cm}$, ${ }^{137} \mathrm{Cs},{ }^{238} \mathrm{Pu},{ }^{239} \mathrm{Pu},{ }^{240} \mathrm{Pu},{ }^{241} \mathrm{Pu},{ }^{242} \mathrm{Pu},{ }^{90} \mathrm{Sr},{ }^{234} \mathrm{U}$ and ${ }^{90} \mathrm{Y}$.
This paper is all but a safety case so that only a limited part of these results is mentioned and commented below to illustrate CESAR computations.

Figure 7 shows the radioactive power produced by a standard $8 \times 8$ PHEBUS fuel sub-assembly as a function of time.

The radioactive power produced by a standard $8 \times 8$ PHEBUS fuel sub-assembly presented in Figure 7 is normalized to 1 ton of initial heavy metal. It corresponds to all energies deposited by $\alpha, \beta, \gamma$ and neutron radiation coming from the sub-assembly. The value before 1993 was very low. It increases after each new experimental phase (cf. Fig. 4 and table in upper corner of Fig. 7) and eventually decreases from the end of the programme on. The main contribution is from fission products. The CESAR GUI includes sorting options in output tables that show at a glance ${ }^{90} \mathrm{Y},{ }^{137} \mathrm{Ba}_{\mathrm{m}}$ and ${ }^{144} \mathrm{Pr}$ are 3 main contributors in early November 2004, whereas it is ${ }^{90} \mathrm{Y}$, ${ }^{137} \mathrm{Ba}_{\mathrm{m}}$ and ${ }^{137} \mathrm{Cs}$ in November 2038. Contribution from the activation of impurities included in the fuel is too low to be mentioned. Such figures are useful for materials transport as computed and shown in Figure 7. However, waste storage issues require investigating over longer periods of time. For instance, after several 1000 years, the decay heat is of the order of a few $\mathrm{W} / \mathrm{T}_{\mathrm{HM}}$ and main contributors are no longer Fission Products but mostly ${ }^{239} \mathrm{Pu},{ }^{240} \mathrm{Pu}$ and ${ }^{241} \mathrm{Am}$, among other heavy nuclides.

The activity of gaseous by-products ${ }^{3} \mathrm{H}$ and ${ }^{85} \mathrm{Kr}$ together goes down from $19.5 \mathrm{~Bq} / \mathrm{T}_{\mathrm{HM}}$ in early November 2004 to $3.6 \mathrm{~Bq} / \mathrm{T}_{\mathrm{HM}}$ in November 2038 and $\sim 95 \%$ comes from ${ }^{85} \mathrm{Kr}$ during this period of time. 
The simplified dose rate at $1 \mathrm{~m}$ coming from ${ }^{154} \mathrm{Eu}$ and ${ }^{137} \mathrm{Ba}_{\mathrm{m}}$ goes down from $16.0 \mathrm{~Gy} / \mathrm{h} . \mathrm{T}_{\mathrm{HM}}$ in early November 2004 to $10.6 \mathrm{~Gy} / \mathrm{h} . \mathrm{T}_{\mathrm{HM}}$ in November 2038 and $~ 99.9 \%$ comes from ${ }^{137} \mathrm{Ba}_{\mathrm{m}}$ during this period of time. In the mean time, the total dose rate (from all isotopes) goes down from $17.7 \mathrm{~Gy} / \mathrm{h} . \mathrm{T}_{\mathrm{HM}}$ in early November 2004 to $10.6 \mathrm{~Gy} / \mathrm{h} . \mathrm{T}_{\mathrm{HM}}$ in November 2038, meaning ${ }^{137} \mathrm{Ba}_{\mathrm{m}}$ is the overall main contributor.

Neutron emissions come from $\boldsymbol{\alpha}, \boldsymbol{n}$ reactions onto oxygen (in oxide fuels) and from spontaneous fission. It goes down from $9.1 \times 10^{4} \mathrm{n} / \mathrm{T}_{\mathrm{HM}}$ in early November 2004 to $1.5 \times 10^{5} \mathrm{n} / \mathrm{T}_{\mathrm{HM}}$ in November 2038 and the share of $\boldsymbol{\alpha}, \boldsymbol{n}$ neutrons remains $\sim 54 \%$ all along. The reason why neutron emissions increase during this period can be confusing. It actually increases mostly during the last main experimental irradiation phase in the PHEBUS facility (the so-called FPT3), which takes place from November 5 th to November 18th 2004. This irradiation causes ${ }^{239} \mathrm{Pu},{ }^{240} \mathrm{Pu}$ and ${ }^{241} \mathrm{Pu}$ concentrations step up with the following respective factors 1.3, 1.9 and 3.0. As they are responsible for most spontaneous fissions and $\boldsymbol{\alpha}$ emissions, it explains why neutron emissions first increase between early and late November 2004 and then decrease.

Several other RTR's have been characterized for decommissioning. Unfortunately, the results are proprietary and cannot be uncovered here.

One single computation for fuel and skeleton is enough to get access to all features required for waste, storage, transportation, reprocessing, safety and criticality as the same irradiation history determines all consecutive radioactive properties.

In the case of a study conducted without CESAR, it would be necessary to develop a lattice physics + depletion and decay calculation scheme and operate it for each sub assembly. It would also require knowing ahead of time when each operation will take place, otherwise computations would have to be performed as many times as operations are delayed or advanced. This burden would cost more with such a computation scheme than with CESAR, all the more so as CESAR does not require a specific skill to update results.

On top of being user friendly, CESAR uses cross section libraries that are validated against a DARWIN reference computation (cf. Sect. 3.2).

This simple and short example is just one small illustration of the benefits that can be drawn from CESAR. There are obviously other applications in a nuclear facility.

\section{Conclusion}

CESAR is a portable evolution tool developed by CEA and co-funded by ORANO. It is intensively used on an industrial scale at the ORANO La Hague reprocessing plant.

It has a high level of validation and a user friendly Graphical User Interface.

It is very fast thanks to pre computed cross section libraries and optimized numerical methods. CESAR can be used in lots of nuclear facilities and in particular in some of CEA RTR's being decommissioned.

\section{References}

1. J.-M. Vidal, R. Eschbach, A. Launay, C. Binet, J.-F. Thro, CESAR5.3: an industrial tool for nuclear fuel and waste characterization with associated qualification, in WM 2012 Conference (Phoenix, Arizona, USA, 2012)

2. H. Bateman, Proc. Camb. Phil. Soc. 16, 423 (1910)

3. A. Santamarina, D. Bernard, P. Blaise, M. Coste, A. Courcelle, T.D. Huynh, C. Jouanne, P. Leconte, O. Litaize, S. Mengelle, G. Noguère, J.-M. Ruggiéri, O. Sérot, J. Tommasi, C. Vaglio, J.-F. Vidal, OECD Nucl. Energy Agency JEFF Rep. 22, 6807 (2009)

4. C. Moler, C. Van Loan, SIAM Rev. 45, 3 (2003)

5. A. Santamarina, D. Bernard, P. Blaise, J.-F. Vidal, APOLLO2.8: a validated code package for PWR neutronics calculations, in ANFM 2009 (Hilton Head Island, SC, USA, 2009)

6. G. Rimpault, The ERANOS code and data system for fast reactor neutronic analyses, in PHYSOR 2002 (Seoul, Korea, 2002)

7. L. San-Felice, R. Eschbach, P. Bourdot, Experimental validation of the DARWIN2.3 package for fuel cycle applications, in PHYSOR 2012 (Knoxville, Tennessee, USA, 2012)

8. L. San-Felice, R. Eschbach, P. Bourdot, Nucl. Technol. 184, $217(2013)$

9. S. Lahaye, T.D. Huynh, A. Tsilanizara, Comparison of deterministic and stochastic approaches for isotopic concentration and decay heat uncertainty quantification on elementary fission pulse, in WONDER 2015 (Aix-enProvence, 2015)

10. [Online]. Available: https://www.qt.io/. [Accessed 1409 2017]

11. [Online]. Available: http://www.salome-platform.org/. [Accessed 1409 2017]

12. T. Haste, F. Payot, C. Manenc, B. Clément, P. March, B. Simondi-Teisseire, R. Zeyen, Nucl. Eng. Des. 261, 333 (2013)

Cite this article as: Guillaume Ritter, Romain Eschbach, Richard Girieud, Maxime Soulard, CESAR5.3: Isotopic depletion for Research and Testing Reactor decommissioning, EPJ Nuclear Sci. Technol. 4, 10 (2018) 